Article

\title{
Relationships between Middle School Students' Smartphone dependency and Aggression: Mediating and Moderating Effects of Ego-Resilience, Parenting Behavior and Peer Attachment
}

\author{
Youn-Joo Um ${ }^{1}$, Yun-Jung Choi ${ }^{1, *}$, and So Yeon Yoo,** \\ 1 Red Cross College of Nursing, Chung-Ang University, Seoul 06974, Korea; 2002242@naver.com (Y.-J.U.) \\ 2 Department of Nursing, Kyungil University, Gyeongbuk 38428, Korea \\ * Correspondence: yunjungchoi@cau.ac.kr (Y.-J.C.); syyoo@kiu.kr (S.Y.Y.); Tel.: +82-2-820-5986 (Y.-J.C.); \\ $+82-53-600-5666$ (S.Y.Y.)
}

\begin{abstract}
This study was conducted to examine the moderating and mediating effect of ego resilience, parenting attitude, and peer attachment in the relation between smartphone dependency and aggression. Participants were 1,863 youths using a smartphone among the first middle school students responded in the 7th Korean Children and Youth Panel Survey (KCYPS) conducted by the National Youth Policy Institute in Korea. The data were analyzed by descriptive statistics, a correlation, and a hierarchical regression analysis. First, ego-resilience showed a partial mediating effect on the relationship between smartphone dependency, aggression and significant moderating effects were revealed. Second, parenting behavior showed a partial mediating effect on the relationship between smartphone dependency and aggression, with no moderating effects seen. Third, peer attachment had a partial mediating effect on the relationship between smartphone dependency and aggression, with no moderating effects seen. The research suggested the mental health and growth of students could be improved by applying various nursing and health care programs to improve ego-resilience, parenting behavior and peer attachment as they grow into adulthood.
\end{abstract}

Keywords: smartphone dependency; aggression; ego-resilience; parenting behavior; peer attachment

\section{Introduction}

The development of digital media technology has brought about a huge change in everyday life. According to the Information and Communication Policy Institute, the usage rate of adolescents has been rapidly increasing from $5.9 \%$ in 2010 to $40 \%$ in 2011 and $92 \%$ in 2017 [18]. The risk group that depends on smartphones for middle school students was also $30.4 \%$, which is relatively high compared to the adult addiction rate of $17.4 \%$, smartphone usage time was also the highest among middle school students [19].

Brenner [5] said that the addictive use of media causes users to experience more problems the younger they are younger. Middle school students especially tend to be sensitive and vulnerable to small problems such as a lack of lack of self-restraint, consideration of others and are most likely to develop aggressive behavior which will continue through their entire lives [21]. Smartphones are more likely to cause school violence problems by blocking off sociality causing students to lose their ability to cope with emotional stress conflicts with peers due to exposure to violent and suggestive applications [17]. Recently, school violence between peers has become the biggest social problem caused by aggression [22]. This increase in aggression needs to be dealt with in depth because it may 
draw physical and verbal violence common among peer groups. This led to an increase in the imitation of adult crimes and the possibility of major social problems occurring later adulthood [20].

There is a statistically significant positive correlation between smartphone dependency and aggression [16]. Lakens[11] reported overuse of smartphones by middle and high school students could make it difficult to control their anger, and it has an effect on increase externalization behavior, such as aggression and delinquency. Ko, Choi, Yang, Lee, and Lee [9] said dependency on smartphones negatively affects adolescents' emotional and behavioral issues such as rebellious behavior disorders.

Until now, research has focused on the biological, social and emotional characteristics of smartphone addicted users [3]. Research, however, is insufficient to prevent smartphone dependency to led to social problems such as aggression. Individuals, households, and society should be concerned because the protective factors effects smartphones have on aggression combined with factors that affect the parenting environment (parenting behavior) and society (peer attachment) can have on an individual's character (ego-resilience) [7].

Also, it would be meaningful to analyze all three of these since individuals of families approach should differ depending on whether it shows a mediated or moderated effect. Through these studies, we aim to identify the impact of smartphone dependency on aggression and the factors of mediation and moderation to obtain basic data that can be used in the development of nursing programs and family counseling, and ultimately to improve the mental health of adolescents to help them grow into healthy adults.

\section{Methods}

\subsection{Data Sources}

This is a secondary study that utilizes data from the middle school freshman panels in the 7th Korean Children and Youth Panel Survey(KCYPS) conducted by the National Youth Policy Institute in Korea [19]. Of 2,351 students in the first grade of middle school, 1,863 men and women who are using smartphones were analyzed. Adolescents answered the questions by writing directly on the questionnaire.

\subsection{Instruments}

\subsubsection{Smartphone dependency}

Lee, Kim, and $\mathrm{Na}$ [13] used the question of dependency on smartphones. A total of 7 questions were used. It used for 4-point Likert scale, including 'very strongly' and 'not quite at all' and all were reversecoded. The higher the score means that adolescents are higher smartphone dependency. The Cronbach's alpha for this measure was .854 .

\subsubsection{Aggression}

The scale was developed by Jo and Im [8] by modifying and using the questions, excluding overlapping questions. A total of 6 questions were used. It used for 4-point Likert scale, including 'very strongly' and 'not quite at all' and all were reverse-coded. A higher score means that adolescents are more aggressive. The Cronbach's alpha for this measure was .809 .

\subsubsection{Ego-resilience}

In this study, the Ego-Resilience Scale (ER) developed by Block and Kremen [4] was translated by Yoo \& Shim [26], used modified and supplemented by Kwon [10]. A total of 14 questions were used, and a 4-point Likert scale was used up to score 4 points for "very strongly" and "not quite at all" and all were reverse-coded. A higher scale score means that adolescents are higher ego-resilience. The Cronbach's alpha for this measure was .831 . 


\subsubsection{Parenting behavior}

Parenting behavior was measured by modified questionnaires of the National Youth Policy Institute in Korea among all of the parenting attitude scale (43 items) produced by Huh [6]. The 21items was categorized into six subscales: 3 items for monitoring, 4 items for affection, 3 items for reasoning, 3 items for inconsistency, 4 items for over-expectation, and 4 items for intrusiveness. It used for 4-point Likert scale, including up to score 4 points for "very strongly" and "not quite at all". The higher the score, the more positive parenting behavior, and the lower the score, the more negative the behavior. The Cronbach's alpha for this measure was .868 .

\subsubsection{Peer attachment}

This scale consisted of 9 questions for each sub-area, with the exception of the question that overlaps the sub-area of the total 25 attached scale (IPPA) developed by Armsden and Greenberg [1]. It used for 4-point Likert scale, including was used up to score 4 points for "very strongly" and "not quite at all" and all were reverse-coded, except for 'be alienated' 3 questions. A higher score means that the more peer attachment. The Cronbach's alpha for this measure was .823.

\subsection{Data analysis}

The data from this study were first used to calculate descriptive statistics for each variable, in order to verify reliability of each measuring tool, Cronbach's $\alpha$ was calculated, and correlation of Pearson was calculated to determine the measured variables. Baron and Kenny [2] hierarchical regression was conducted to see if ego-resilience, parenting behavior, and peer attachment served as mediation between smartphone dependency and aggression, and a Sobel test was conducted to test the statistical significance of the mediated effects. Finally, a hierarchical regression was performed to test the moderation effects of ego-resilience, parenting behavior, and peer attachment variables in relationships that smartphone dependency affect aggression.

\section{Results}

\subsection{Descriptive statistics}

The results of calculating the score range, the minimum value, the maximum value, and the mean and the standard deviation to examine the general trend of the dependency of smartphone, aggression, ego-resilience, the parenting behavior and the peer attachment are shown in Table 1 . The study was conducted on 1863 students who used smartphones the first grade in the middle school which responded to the questionnaire.

Table 1. Descriptive statistics on research variables $(\mathrm{N}=1,863)$

\begin{tabular}{llllll}
\hline variable & score range & Min & Max & M & SD \\
\hline $\begin{array}{l}\text { Smartphone } \\
\text { dependency }\end{array}$ & $7-28$ & 7 & 28 & 17.26 & 4.35 \\
\hline Aggression & $6-24$ & 6 & 22 & 10.78 & 3.13 \\
\hline $\begin{array}{l}\text { Ego- resilience } \\
\text { 14-48 }\end{array}$ & 21 & 56 & 39.80 & 5.41 \\
\hline $\begin{array}{l}\text { Parenting } \\
\text { behavior }\end{array}$ & $21-84$ & 33 & 84 & 61.21 & 8.18 \\
\hline \begin{tabular}{l} 
Peer attachment \\
\hline
\end{tabular} & $9-36$ & 14 & 36 & 28.28 & 3.77 \\
\hline
\end{tabular}

\subsection{Correlation with major variables}

The results are shown in Table 2. The smartphone dependency showed a significant correlation with all variables. Specifically, the dependency on smartphones has shown a positive correlation 
between aggression $(\mathrm{r}=.27, \mathrm{p}<.01)$, and negative correlation between ego - resilience $(\mathrm{r}=-.27, \mathrm{p}<.01)$, parenting behavior $(\mathrm{r}=-.25, \mathrm{p}<.01)$ and peer attachment $(\mathrm{r}=-.12, \mathrm{p}<.01)$. Aggression showed a markedly negative correlation between ego-resilience $(\mathrm{r}=-.23, \mathrm{p}<.01)$, parenting behavior $(\mathrm{r}=-.29, \mathrm{p}<.01)$ and peer attachment $(\mathrm{r}=-.25, \mathrm{p}<.01)$. Ego - resilience showed a significantly positive correlation between parenting behavior $(\mathrm{r}=.25, \mathrm{p}<.01)$, peer attachment $(\mathrm{r}=.34, \mathrm{p}<.01)$. Parenting attitude was significantly positive correlation to peer attachment $(\mathrm{r}=.46, \mathrm{p}<.01)$.

Table 2. Correlation between research variables

\begin{tabular}{llllll}
\hline variable & $\begin{array}{l}\text { smartphone } \\
\text { dependency }\end{array}$ & aggression & ego-resilience & $\begin{array}{l}\text { parenting } \\
\text { behavior }\end{array}$ & peer attachment \\
\hline $\begin{array}{l}\text { smartphone } \\
\text { dependency }\end{array}$ & 1 & & & \\
\hline aggression & $.27^{* *}$ & 1 & & \\
\hline ego-resilience & $-.27^{* *}$ & $-.23^{* *}$ & 1 & 1 \\
\hline parenting behavior & $-.25^{* *}$ & $-.29^{* *}$ & $.25^{* *}$ & \\
\hline$*$ p $<.01$ & & & &
\end{tabular}

3.3. Mediating effect of ego-resilience, parenting behavior, and peer attachment on the relationship between smartphone dependency and aggression

Table 3 shows the mediating effects of ego-resilience, parenting behavior, and peer attachment in the relationship between smartphone dependency and aggression. First, we analyzed mediating effect of ego-resilience. In step 1, we analyzed the effect of independent variable (smartphone dependency) on the dependent variables (aggression). This confirmed that dependency on smartphones had a significant effect on aggression $(\beta=.27, p<.001)$.

In step 2, we analyzed the effect of independent variable (smartphone dependency) on the mediation variables (ego-resilience). As a result, the smartphone dependency showed significant results $(\beta=-.23 p<.001)$ on ego-resilience.

In step 3, independent variables (smartphone dependency) and mediation variables (ego-resilience) were injected at the same time to validate their influence on the dependent variables (aggression). As a result, both independent variables $(\beta=.22, p<.001)$ and mediation variables $(\beta=-.17, p<.001)$ had significant effects, but, the effect of an independent variable $(\beta=.22, p<.001)$ was reduced than that of a dependent variable except mediation variables $(\beta=.27, p<.001)$. Therefore, ego-resilience (mediation variables) was found to partial mediation between the dependency of smartphone and aggression. The results of the Sobel test showed a significant level $(Z=7.21, p<.001)$.

Second, we analyzed mediating effect of parenting behavior. In step 2, the effect of the independent variable (smart phone dependency) on the mediation variable (parenting attitude) was analyzed. As a result, smartphone dependency showed significant results for parenting behavior $(\beta=-.25, p<.001)$.

In step 3, independent variables (smartphone dependency) and mediation variable (parenting behavior) were simultaneously injected to verify their influence on dependent variables (aggression). As a result, both independent variables $(\beta=.21, p<.001)$, and mediation variables $(\beta=-.23, p<.001)$ had a significant effect. However, the effect of the independent variable $(\beta=.21, p<.001)$ was reduced than that of dependent variable $(\beta=.27, p<.001)$ except mediation variables $(\beta=.27, p<.001)$. Therefore, parenting behavior (mediation variables) was found to partial mediation between the smartphone dependency and aggression. The results of the sobel test showed a significant level $(Z=7.42, p<.001)$.

Third, we analyzed mediating effect of peer attachment. In step 2, the effect of the independent variable (smart phone dependency) on the mediation variable (peer attachment) was analyzed. As a result, smartphone dependency showed significant results for peer attachment $(\beta=-.12, p<.001)$. 
Table 3. Mediating effect of ego-resilience, parenting behavior and peer attachment on the relationship between smartphone dependency and aggression

\begin{tabular}{|c|c|c|c|c|c|c|c|c|}
\hline Mediation & step & $\begin{array}{c}\text { Dependen } \\
t\end{array}$ & Independent & B & S.E & $\beta$ & $\mathbf{t}$ & $R^{2}$ \\
\hline \multirow[t]{7}{*}{$\begin{array}{l}\text { ego- } \\
\text { resilience }\end{array}$} & \multirow[t]{2}{*}{1} & \multirow[t]{2}{*}{ aggression } & $\begin{array}{l}\text { smartphone } \\
\text { dependency }\end{array}$ & .19 & .02 & .27 & $11.9^{* * *}$ & .27 \\
\hline & & & \multicolumn{6}{|c|}{$\mathrm{F}=141.79^{* * *}, \mathrm{VIF}=1.00$, Durbin-Watson $=1.84$} \\
\hline & \multirow[t]{2}{*}{2} & \multirow[t]{2}{*}{$\begin{array}{l}\text { ego- } \\
\text { resilience }\end{array}$} & $\begin{array}{l}\text { smartphone } \\
\text { dependency }\end{array}$ & -.28 & .03 & -.23 & -10.00 & .051 \\
\hline & & & \multicolumn{6}{|c|}{$\mathrm{F}=100.06^{* * *}, \mathrm{VIF}=1.00$, Durbin-Watson=1.67 } \\
\hline & \multirow[t]{3}{*}{3} & \multirow[t]{3}{*}{ aggression } & $\begin{array}{l}\text { smartphone } \\
\text { dependency }\end{array}$ & .16 & .02 & .24 & $10.00^{* * *}$ & \multirow[t]{2}{*}{.10} \\
\hline & & & ego-resilience & -.10 & .01 & -.17 & $-7.91^{* * *}$ & \\
\hline & & & \multicolumn{6}{|c|}{$\mathrm{F}=104.51^{* * *}, \mathrm{VIF}=1.05$, Durbin-Watson=1.86 } \\
\hline \multirow[t]{5}{*}{$\begin{array}{l}\text { parenting } \\
\text { behavior }\end{array}$} & \multirow[t]{2}{*}{2} & \multirow[t]{2}{*}{$\begin{array}{l}\text { parenting } \\
\text { behavior }\end{array}$} & $\begin{array}{l}\text { smartphone } \\
\text { dependency }\end{array}$ & -.47 & .04 & -.25 & $-11.02^{* * *}$ & .061 \\
\hline & & & \multicolumn{5}{|c|}{$\mathrm{F}=121.48^{* * *}, \mathrm{VIF}=1.0$, Durbin-Watson $=1.832$} & \\
\hline & \multirow[t]{3}{*}{3} & \multirow[t]{3}{*}{ aggression } & $\begin{array}{l}\text { smartphone } \\
\text { dependency }\end{array}$ & .15 & .02 & .21 & $9.29^{* * *}$ & \multirow[t]{2}{*}{.12} \\
\hline & & & parenting behavior & -.09 & .01 & -.23 & $-10.41^{* *}$ & \\
\hline & & & \multicolumn{6}{|c|}{$\mathrm{F}=129.21^{* * *}, \mathrm{VIF}=10.65$, Durbin-Watson=1.831 } \\
\hline \multirow[t]{5}{*}{$\begin{array}{c}\text { peer } \\
\text { attachment }\end{array}$} & \multirow[t]{2}{*}{2} & \multirow[t]{2}{*}{$\begin{array}{c}\text { peer } \\
\text { attachment }\end{array}$} & $\begin{array}{l}\text { smartphone } \\
\text { dependency }\end{array}$ & -.10 & .02 & -.12 & $-5.11^{* * *}$ & .014 \\
\hline & & & \multicolumn{6}{|c|}{$\mathrm{F}=26.10^{* * *}, \mathrm{VIF}=1.00$, Durbin-Watson $=1.61$} \\
\hline & \multirow[t]{3}{*}{3} & \multirow[t]{3}{*}{ aggression } & $\begin{array}{l}\text { smartphone } \\
\text { dependency }\end{array}$ & .17 & .02 & .24 & $10.97^{* * *}$ & \multirow[t]{2}{*}{.12} \\
\hline & & & peer attachment & -.18 & .02 & -.22 & $-9.90^{* * *}$ & \\
\hline & & & $\mathrm{F}=123.6$ & $\mathrm{VIF}=$ & Dur & Wats & .85 & \\
\hline
\end{tabular}

$* * *<.001$

In step 3, independent variables (smartphone dependency) and mediation variable (parenting attitude) were simultaneously injected to verify their influence on dependent variables (aggression). As a result, both independent variables $(\beta=.24, \mathrm{p}<.001)$, and mediation variables $(\beta=-.22, p<.001)$ had a significant effect. However, the effect of the independent variable $(\beta=.24, p<.001)$ was reduced than that of dependent variable $(\beta=.27, p<.001)$ except mediation variables. Therefore, peer attachment (mediation variables) was found to partial mediation between the smartphone dependency and aggression. The results of the sobel test showed a significant level $(Z=4.54 \mathrm{p}<.001)$.

3.4. Moderating effect of ego-resilience, parenting behavior, and peer attachment on the relationship between smartphone dependency and aggression

Table 4 shows the moderating effects of ego-resilience, parenting behavior, and peer attachment in the relationship between smartphone dependency and aggression. First, we analyzed moderating effect of ego-resilience.

In step 3, where independent variables, moderating variables, and interaction terms are all injected, smartphone dependency $(\beta=.228, p<.001)$, and ego-resilience $(\beta=-.186, p<.001)$, interaction terms $(\beta=-.047, p<.05)$ were shown to significantly predict aggression, and the explanatory power of model was $10 \%$. Ego-resilience has both significant mediating and moderation effect. 
Table 4. Moderating effect of ego-resilience, parenting behavior and peer attachment on the relationship between smartphone dependency and aggression

\begin{tabular}{|c|c|c|c|c|c|c|c|}
\hline Moderation & step & Independent & B & S.E & $\beta$ & $t$ & $R^{2}$ \\
\hline \multirow[t]{6}{*}{ ego-resilience } & 1 & $\begin{array}{l}\text { smartphone } \\
\text { dependency }\end{array}$ & .192 & .016 & .266 & $11.908^{* * *}$ & .071 \\
\hline & \multirow[t]{2}{*}{2} & $\begin{array}{l}\text { smartphone } \\
\text { dependency }\end{array}$ & .162 & .016 & .266 & $10.003^{* * *}$ & \multirow[t]{2}{*}{.101} \\
\hline & & ego-resilience & -.103 & .013 & $\begin{array}{c}- \\
.178\end{array}$ & $-7.909^{* * *}$ & \\
\hline & \multirow[t]{3}{*}{3} & $\begin{array}{l}\text { smartphone } \\
\text { dependency }\end{array}$ & .164 & .016 & .228 & $10.113^{* * *}$ & \multirow[t]{3}{*}{.103} \\
\hline & & ego-resilience & -.108 & -013 & $\begin{array}{c}- \\
.186\end{array}$ & $-8.148^{* *}$ & \\
\hline & & $\begin{array}{c}\text { smartphone } \\
\text { dependency } \\
\text { ×ego-resilience }\end{array}$ & -.005 & .003 & $\begin{array}{c}- \\
.047\end{array}$ & $-2.090^{*}$ & \\
\hline \multirow[t]{5}{*}{$\begin{array}{l}\text { parenting } \\
\text { behavior }\end{array}$} & \multirow[t]{2}{*}{2} & $\begin{array}{l}\text { smartphone } \\
\text { dependency }\end{array}$ & .150 & .016 & .208 & $9.288^{* * *}$ & \multirow[t]{2}{*}{.122} \\
\hline & & parenting behavior & -.090 & .009 & -.234 & $10.413^{* * *}$ & \\
\hline & \multirow[t]{3}{*}{3} & $\begin{array}{l}\text { smartphone } \\
\text { dependency }\end{array}$ & .152 & .016 & 211 & $9.371^{* * *}$ & \multirow[t]{3}{*}{.147} \\
\hline & & parenting behavior & -.091 & .009 & -237 & $10.513^{* * *}$ & \\
\hline & & $\begin{array}{c}\text { smartphone } \\
\text { dependency } \\
\times \text { parenting behavior }\end{array}$ & -.002 & .002 & -.032 & -1.452 & \\
\hline \multirow[t]{5}{*}{$\begin{array}{c}\text { peer } \\
\text { attachment }\end{array}$} & \multirow[t]{2}{*}{2} & $\begin{array}{l}\text { smartphone } \\
\text { dependency }\end{array}$ & .173 & .016 & .241 & $10.965^{* * *}$ & \multirow[t]{2}{*}{.117} \\
\hline & & peerattachment & -.180 & .018 & -.217 & $-9.902^{* * *}$ & \\
\hline & \multirow[t]{3}{*}{3} & $\begin{array}{l}\text { smartphone } \\
\text { dependency }\end{array}$ & .172 & .016 & .239 & $10.748^{* * *}$ & \multirow[t]{3}{*}{.117} \\
\hline & & peer attachment & -.180 & .018 & -217 & $-9.871^{* * *}$ & \\
\hline & & $\begin{array}{c}\text { smartphone } \\
\text { dependency } \\
\text { xpeer attachment }\end{array}$ & -.002 & .004 & -.012 & .561 & \\
\hline
\end{tabular}

${ }^{* * *} p<.001,{ }^{* *} p<.01,{ }^{*} p<.05$

Second, we analyzed moderating effect of parenting behavior. The analysis showed that step 1 $(\beta=.266, p<.001)$ and step $2(\beta=-.234, p<.001)$ had a significant impact on aggression. However, we looked at the impact of both independent and dependent variables and interaction terms on aggression in step 3 , but were not statistically significant. In other words, parenting behavior affect aggression, but there has been no effect of moderation parenting behavior between smartphone dependency and aggression. Third, we analyzed moderating effect of peer attachment.

The analysis showed that the step $1(\beta=.266, p<.001)$ and step $2(\beta=-.217, p<.001)$ had a significant impact on aggression. However, we looked at the impact of both independent and dependent variables and interaction terms on aggression in step 3, but were not statistically significant.

\section{Discussion}

The purpose of this study is to identify factors that mediating and moderating effect a middle school student's dependency on smartphones in relation to aggression and help their healthy 
psychological growth. To this end, the results of the final analysis of 1,863 smartphone users among the data collected by the 7th Korean Children and Youth Panel Survey(KCYPS) conducted by the National Youth Policy Institute in Korea [19] are as follows.

First, ego-resilience had partial mediation and moderation effects in relation to dependency on Smartphones and aggression. Pre-research found that ego-resilience has a partial mediated effect in relation to smartphone addiction, and ego-resilience serves as mediation variables to reduce the level of aggression [25]. These results show that adolescents can mediate and moderate their smartphones dependency by improving their ego-resilience to prevent their more aggressive behaviors.

Second, the parenting behavior has shown partial mediation in relation to smartphone dependency and aggression, but there was no moderation effect. This is in line with a study that stated that aggression mediates between parenting behavior toward smartphone addiction, and that aggression affects the relationship between parenting behavior and smartphone dependency the most [24]. These findings suggest the importance of access to improving appropriate parenting behavior in the prevention and treatment of aggression in young people who rely heavily on smartphones. But, parenting behavior have shown to be not significant as a moderation variable when their smartphones dependency affects aggression. Although smartphones dependency and parenting behavior significantly affect aggression, it is found that their influence on aggression does not change depending on the level of parenting attitude. That is, the relationship between the two variables was significant, because smartphone dependency has a greater impact on aggression than that of parenting behavior, the impact of parenting behavior has been relatively reduced.

Third, peer attachment showed partial mediation in relation to smartphone dependency and aggression, but there was no moderation effect. This is in line with research suggesting overuse of smartphones is a factor in lowering the quality of peer relationships, and the higher the degree of alienation felt from peer relationships, the higher the smartphones dependency [15]. These findings suggest the importance of improving peer relationships in the event of involvement in the prevention and treatment of aggression in adolescents who rely heavily on smartphones. But, peer attachment has shown to be not significant as a moderation variable when their smartphones dependency affects aggression. Although smartphones dependency and peer attachment significantly affect aggression, it is found that their influence on aggression does not change depending on the level of peer attachment. Pre- research found that social support acts as a control variable when accompanied by psychological factors [23]. Such a phenomenon cannot be controlled by social support, such as peer attachment, and can be interpreted to lead to reduced aggression when the protection factor of ego-resilience is first applied.

After all, we should try to ensure that interventions involving individuals, households, and schools are achieved in order to prevent and treat overuse of smartphones in middle school students.

The limitations of this study and suggestions for further study are as follows: First, there may be limitations in reflecting the overall scale by using only some of the scale questions used in the KCYPS. Further studies will need to be done using scales and all questions. Second, since the measurement tools used in this study used ego-reporting questionnaires, they may be affected by personal factors (question interpretation skills, subjective accidents). Therefore, in subsequent studies, access is needed through a variety of research methods.

\section{Conclusion}

Here are three main reasons why the research findings can contribute to the health of adolescents: First, it is meaningful that middle school students' dependency on smartphones on their aggression has been comprehensively checked for mediation and moderation variables in terms of individuals, households and society. It was checked whether personal capabilities, support from parents, and support functions of friends could create synergy with each other.

Second, ego-resilience controlled the impact of smartphone dependency on aggression and the dependency on smartphones was mediating this relationship with aggression. These findings suggest 
that the development of 'ego-resilience' is important to reduce the side effects of youth in an environment where smartphones are used on a daily basis and to help them.

Third, for middle school students who are highly dependent on smartphones, a variety of programs and activities are needed to improve parenting attitude and peer relationships. This will reduce the impact of smartphone dependency on aggression through parenting behavior and peer attachment.

\section{Reference}

1. Armsden, G. C., \& Greenberg, M. T. (1987). The inventory of parent and peer attachment: Individual differences and their relationship to psychological well-being in adolescence. Journal of Youth and Adolescence, 16(5), 427-454. https://doi.org/10.1007/BF02202939.

2. Baron, R. M., \& Kenny, D. A. (1986). The moderator-mediator variable distinction in social psychological research : Conceptual, strategic, and statistical considerations. Journal of Personality and Social Psychology, 51(6), 1173-1182. https://doi.org/10.1037/0022-3514.51.6.1173.

3. Bianchi, A., \& Phillips, J. G. (2005). Psychological predictors of problem mobile phone use. Cyberpsychology $\mathcal{E}$ Behavior, 8(1), 39-51. https://doi.org/10.1089/cpb.2005.8.39.

4. Block, J., \& Kremen, A. M. (1996). IQ and ego-resilience: Conceptual and empirical connections and separateness. Journal of Personality \& Social Psychology, 70(2), 349-362. http://doi.org/10.1037/00223514.70.2.349.

5. Brenner, V. (1997). Psychology of computer use: XLVII. parameters of internet use, abuse and addiction: the first 90 days of the internet usage survey. Psychological Report, 80, 879-882. http://doi.org/10.2466/pr0.1997.80.3.879.

6. Huh M. Y. (1999) The study for the development and validation of 'parenting behavior inventory' perceived by adolescents (doctoral dissertation). Ewha Womans University; Seoul, Korea. Retrieved from http://lib.ewha.ac.kr/search/media/url/CAT000000528537

7. Jessor, R., Van Den Bos, J., Vanderryn, J., Costa, F. M., \& Turbin, M. S. (1995). Protective factors in adolescent problem behavior: Moderator effects and developmental change. Developmental Psychology, 31(6), 923-933. https://doi.org/10.1037/0012-1649.31.6.923

8. Jo, B. H., \& Im, G. H. (2003). Development and validation of emotional or behavior problems scale. The Korean journal of counseling and psychotherapy, 15(4), 729-746.

9. Ko, M., Choi. S., Yang. S., Lee, J., \& Lee, U. (2015, September). FamiLync: facilitating participatory parental mediation of adolescents' smartphone use. UbiComp '15 Proceedings of the 2015 ACM International Joint Conference on Pervasive and Ubiquitous Computing (pp. 867-878), Osaka, Japan. doi/10.1145/2750858.2804283

10. Kwon, J. E. (2003). The relation of ego-resilience, parent and peer attachment, and problem-solving (master's thesis). Ewha Womans University, SEOUL.

11. Lakens, D. (2013). Using a smartphone to measure heart rate changes during relived happiness and anger. IEEE Transactions on Affective Computing, 4(2), 238-241. https://doi.org/10.1109/T-AFFC.2013.3

12. Lee, H. S., \& Chung, O. B. (2004). The Relationship between the adolescent's perception of marital conflict and the adolescent's offensive character. Korean Home Economics Education Association, 16(1), 47-62.

13. Lee, S., Kim, H., \& Na, E (2002). Adolescents' cellular phone using and it's effects on them. Seoul: Research Report 2002-1. Retrived from Institute of Sociomental Health, Samsung Life Public Welfare Foundation website: 03\&MENU_ID=003012\&DP_CODE=MHI http://www.samsunghospital.com/dept/main/index.do?cPage=

14. Lin, T. T. C. \& Chiang, Y.(2017). Investigating predictors of smartphone dependency symptoms and effects. Smartphone dependency predictors and effects on academic performance, improper phone use and perceived sociability. International Journal of Mobile Communications, 15(6), 655-676. https://doi.org/10.1504/IJMC.2017.10005647.

15. Liu, C., \& Kuo, F. (2007). A study of internet addiction through the lens of the interpersonal theory. CyberPsychology \& Behavior, 10(6), 799-805. https://doi.org/10.1089/cpb.2007.9951.

16. Liu, C., Lin, S., Pan, Y., \& Lin, Y. (2016). Smartphone gaming and frequent use pattern associated with smartphone addiction. Medicine, 95(28), 1-4. https://doi.org/10.1097/MD.0000000000004068. 
17. Miner, A. S., Milstein, A., \& Schueller, S. (2016). Smartphone-based conversational agents and responses to questions about mental health, interpersonal violence, and physical health. JAMA Internal Medicine, 176(5), 619 - 625. http://doi.org/10.1001/jamainternmed.2016.0400.

18. National Information Society Agency. (2017). The survey on smart phone overdependence 2017: Ministry science and ICT, NIAV-RER-C-17042. Retrieved from https://www.nia.or.kr/site/nia_kor/ex/bbs/List.do?cbIdx=65914.

19. National Youth Policy Institute. (2017). Korea children and youth panel survey, $7^{\text {th }}$ survey, Sejong: Korea National Youth Policy Institute. Retrieved http://archive.nypi.re.kr/brdartcl/boardarticleList.do?brd_id=BDIDX_k9Fd9oFi29nooCcJ7kX1I4\&srch_ctgry _idx=CTIDX00042\&menu_nix=qZc474Ak

20. Olweus, D. (1994). Bullying at school: basic facts and effects of a school based intervention program. The Journal of Child Psychology and Psychiatry, 35(7), 1171-1190. http://doi.org/ 10.1111/j.1469-7610.1994.tb01229.x.

21. Schlomer, G. L., Cleveland, H. H., Vandenbergh, D. J., Feinberg, M. E., Neiderhiser, J. M., Greenberg, M. T., . . Redmond, C. (2015). Developmental differences in early adolescent aggression: A Gene $\times$ Environment $\times$ Intervention Analysis. Journal of youth and adolescence, 44(3), 581-597. http://doi.org/10.1007/s10964-0140198-4.

22. Tan, K., Gorman-Smith. D., Schoeny, M., \& Choi, Y. (2018). Patterns of social-emotional needs and trajectories of aggression and substance use among middle school boys. The Journal of Early Adolescence, 00(0), 1-27. https://doi.org/10.1177/0272431618812740.

23. Um, Y., \& Kim, S. (2016). The relationship between stress and depression for adolescents of single-parent families: moderating Effect of self-esteem, quality of family relationship and community support. Korean Journal of Family Welfare, 21(3). 367-392. https://doi.org/10.13049/kfwa.2016.21.3.1.

24. Vaterlaus, J. M., Beckert, T. E., Tulane, S., \& Bird, C. V. (2014). They always ask what I'm doing and who I'm talking to": Parental mediation of adolescent interactive technology use. Marriage \& Family Review, 50, 691713. http://doi.org/10.1080/01494929.2014.938795.

25. Wisniewski, P., Jia, H., Wang, N., Zheng, S., Xu, H., Rosson, M. B., and John, M. C. (2015). Resilience Mitigates the Negative Effects of Adolescent Internet Addiction and Online Risk Exposure. CHI '15 Proceedings of the 33rd Annual ACM Conference on Human Factors in Computing Systems, Republic of Korea, 4029-4038. http://dx.doi.org/10.1145/2702123.2702240.

26. Yoo, S., \& Shim, H. (2002). Psychological protective factors in resilient adolescents in Korea. Korean Journal of Educational Psychology, 16(4), 189-206. 